\title{
A geração de conhecimento e as inovações sócio-organizativas da agricultura familiar: $O$ caso de Dom Feliciano, $R S$
}

\author{
Leonardo Xavier Da Silva \\ Universidade Federal do Rio Grande do Sul - Porto Alegre - RS - Brasil \\ ORCID: https://orcid.org/0000-0002-1376-8081 \\ Dagoberto de Dios Hernández \\ Universidade Federal do Rio Grande do Sul - Porto Alegre - RS - Brasil \\ ORCID: https://orcid.org/0000-0001-7252-3140 \\ Jesús Antonio Madera Pacheco \\ Universidad Autónoma de Nayarit - Tepic - Nayarit - México \\ ORCID: http://orcid.org/0000-0001-5801-2686
}

\begin{abstract}
Resumo
Dom Feliciano é um município brasileiro localizado na região Centro-Sul do estado de Rio Grande do Sul. Cerca de $90 \%$ da sua população são descendentes de poloneses, e pela sua estrutura populacional e socioeconômica trata-se de um território rural que possui nas atividades agropecuárias, entre elas o tabaco, contribuições importantes ao PIB municipal. No ano 2000 a realidade local se manifestava complexa, através de algumas medições socioeconômicas que colocavam o município nas últimas posições do desenvolvimento socioeconômico estadual. No meio dessa conjuntura, a gênese de um processo social começa a se constituir a partir de um exercício de Planejamento Participativo Municipal (PPM) levado ao município por articuladores da Emater/RS, em 2001. O objetivo do presente trabalho é analisar a geração de conhecimento e a construção de inovações sociais da agricultura familiar em Dom Feliciano ao longo das duas décadas do século XXI. Este trabalho é abordado mediante uma metodologia qualitativa e é baseado num estudo de caso que usa ferramentas de pesquisa etnográfica, apoiando-se na Perspectiva Orientada ao Ator (POA) como referencial teórico-analítico. Foi possível documentar a construção de alguns dispositivos sociais, na forma do Conselho Municipal de Desenvolvimento Rural (CMDR) e do Plano Municipal de Desenvolvimento Rural (PMDR), que se revelaram inovações, donde a participação de diversos atores e associações comunitárias promoveram a formação de capital social e de ações organizativas como a Cooperativa Agropecuária Centro-Sul (Coopacs), articulando e materializando as demandas e necessidades comunitárias em torno a uma ideia própria de desenvolvimento local e com autonomia dos atores.
\end{abstract}

Palavras-chave: Participação. Atores. Autonomia. Associações. Coopacs. 


\title{
The knowledge generation and the socio-organizational innovations of the family
} farming. The case of Dom Feliciano, RS

\begin{abstract}
Dom Feliciano is a Brazilian municipality located in the south-central region of Rio Grande do Sul State; around $90 \%$ of its population are polish descent and due its population and socioeconomic structure, it is a rural territory whose agriculture activities, like tobacco, contribute significantly to the municipality GNP (gross domestic product). In the year 2000, the local reality manifested complex through its socioeconomic indicators. At this juncture, the genesis of a social process starts to constitute on the basis of a municipal participating planning exercise made by articulators of Emater/RS, in 2001. The present paper, through a qualitative methodology and ethnographic investigation tools, supported in the actor's perspective as theoretical-analytical referential, aims to analyze the generation of knowledge and the social innovations construction of the family farming in Dom Feliciano, during the last two decades of the XXI Century. It was documented the construction of social devices in the form of the Municipal Council for Rural Development and the Municipal Plan for Rural Development; As well as innovations where the participation of diverse actors and community associations promoted the creation of social capital and organization actions, like the Cooperativa Agropecuaria Centro Sul (Coopacs), which articulates and materializes the demands and necessities of the community around the own view of local development and with the actors autonomy.
\end{abstract}

Key words: Participation. Actors. Autonomy. Associations. Coopacs.

\section{La generación de conocimiento y las innovaciones sócio-organizativas de la agricultura familiar. El caso de Dom Feliciano, RS}

\section{Resumen}

Don Feliciano es un municipio brasileño localizado en la región Centro-Sur del estado de Rio Grande del Sur; alrededor del 90\% de su población es de ascendencia polaca y, por su estructura poblacional y socioeconómica, se trata de un territorio rural cuyas actividades agropecuarias, entre ellas el tabaco, contribuyen de manera importante al PIB municipal. En el año 2000, la realidad local se manifestaba compleja a través de indicadores socioeconómicos que ubicaban este municipio en las últimas posiciones con respecto al desarrollo socioeconómico del estado. En medio de esta coyuntura, la génesis de un proceso social comienza a constituirse a partir de un ejercicio de Planeación Municipal Participativa realizado por articuladores de la Emater/RS en 2001. El presente trabajo, mediante una metodología cualitativa y herramientas de investigación etnográfica, apoyándose en la Perspectiva Orientada al Actor como referencial teórico-analítico, tiene como objetivo analizar la generación de conocimiento y la construcción de innovaciones sociales de la agricultura familiar en Don Feliciano durante las dos últimas décadas del siglo XXI. Se documentó la construcción de dispositivos sociales en la forma del Consejo Municipal para el Desarrollo Rural y del Plan Municipal para el Desarrollo Rural; así como innovaciones donde la participación de diversos actores y asociaciones comunitarias promovieron la formación de capital social y de acciones organizativas, como la Cooperativa Agropecuaria Centro-Sul (Coopacs), que articula y materializa las demandas y necesidades de la comunidad en torno a su idea propia de desarrollo local y con la autonomía de los actores.

Palabras clave: Participación. Actores. Autonomía. Asociaciones. Coopacs. 


\section{Introdução}

A virada do século XXI apresentou para o município de Dom Feliciano, no Estado do Rio Grande do Sul, uma conjuntura crítica, ou, alternativamente, uma janela de oportunidade, sobretudo após a trajetória percorrida que se tem experimentado na busca por uma mudança social e melhor qualidade de vida. A situação crítica vivenciada no começo dos anos 2000 é demonstrada na última posição no ranking do Índice de Desenvolvimento Humano Municipal (IDH-M) (ATLAS, 2019) e pobreza de nível estado (o qual era por demais preocupante, ao ponto de se tornar num desafio para a diversidade de atores presentes no território), que fez com que seus atores buscassem o meio para mudar este status.

Dom Feliciano é escolhido para o caso de estudo aqui apresentado, principalmente pelas características sociais e econômicas, assim como pela estrutura populacional em que o município se encontrava. Para o ano 2018 havia uma população estimada em torno de 15.338 pessoas, donde acima de $75 \%^{1}$ moravam no interior caracterizado como rural (IBGE, 2010). Em Dom Feliciano, como em alguns outros municípios do Rio Grande do Sul e da região Centro-Sul deste Estado, as atividades agropecuárias, entre elas a cultura do tabaco, são consideradas a principal atividade, em termos de fonte de renda municipal. No entanto, é necessário relativizar que se trata de uma atividade importante, sobretudo na geração de emprego, assim como em número de famílias produtoras e outros rendimentos produtivos associados a ela, que em conjunto fazem aportes à renda municipal total.

Um exercício multinível e multi-ator, através de um processo de planejamento regional e municipal, dinamizado inicialmente por extensionistas da Emater/RS, abriu espaço à inclusão e à participação de diferentes atores, para a gênese de um processo de mudança social. Essa diversidade de participantes e o reconhecimento de desafios socioeconômicos possibilitaram que esse planejamento pudesse superar a temporalidade e a espacialidade, ainda com os percalços, dificuldades e retrocessos próprios de uma experiência dessas características. Após quase duas décadas da emergência e continuidade desse processo, é possível asseverar que em Dom Feliciano está em curso a construção de uma trajetória de desenvolvimento que apresenta elementos diferenciadores e um ritmo próprio que pode ser julgado como diferente de outras experiências.

Com a ajuda da Perspectiva Orientada ao Ator (POA), base analítica proposta, por exemplo, por Long (2007), e uma metodologia qualitativa, que utiliza um estudo de caso e ferramentas de pesquisa etnográfica para abordar o objeto de estudo, temse como o objetivo, analisar a construção e a geração de conhecimento e as inovações sociais para a agricultura familiar em Dom Feliciano. Estas foram e estão sendo construídas ao longo de quase duas décadas, após um processo de planejamento participativo introduzido pelo poder público municipal.

Para tanto, cabe fazer as seguintes perguntas: como tem se dado a geração de conhecimento e as inovações para a agricultura familiar em Dom Feliciano ao longo das últimas duas décadas? Quais foram os dispositivos e arranjos sociotécnicos que materializam o conhecimento e as inovações em torno de um exercício gerenciado pelos atores locais/rurais? Qual seria o diferencial das experiências

\footnotetext{
${ }^{1}$ Esta participação relativa diz respeito aos dados do Censo Demográfico de 2010 (IBGE, 2010).
} 
geradas em um município como Dom Feliciano para a temática de geração de conhecimentos e inovações para a agricultura familiar no Brasil?

O presente trabalho encontra-se composto, além desta introdução, do arcabouço teórico baseado na Perspectiva Orientada ao Ator, de maneira a se apresentar como se realiza pelos atores rurais a produção de conhecimento e de novidades na agricultura familiar, de modo que sejam os insumos teórico-conceituais para o entendimento da temática estudada. Em seguida, a metodologia expressa a forma como a realidade local do município foi estudada. Logo depois, realiza-se uma breve descrição do recorte empírico a ser estudado, em que se apresenta a realidade local de Dom Feliciano e uma reconstrução histórica da chegada e continuidade do processo de Planejamento Participativo a nível regional e municipal. Por conseguinte, os resultados apresentam o modo como a geração e a construção de conhecimento se realizou em Dom Feliciano e em que inovações se materializaram esses conhecimentos, destacando-se o Conselho Municipal de Desenvolvimento Rural (CMDR) e as associações comunitárias, o Plano Municipal de Desenvolvimento Rural (PMDR) e a Cooperativa Agropecuária Centro-Sul (Coopacs), além de outros que estão em curso. Encerra-se o trabalho com as reflexões finais de modo a apresentar os desafios futuros em torno do processo vivenciado em Dom Feliciano.

\section{0 arcabouço teórico para o entendimento da construção e geração de conhecimento e inovações sócio-organizativas da agricultura familiar em Dom Feliciano}

Segundo alguns autores, há em curso um processo silencioso de mudança de base produtiva e tecnológica da agricultura e da produção agroalimentar no Brasil. Seus proponentes asseguram se tratar de um processo que é descontinuo e que ocorre em situações e contextos que na maioria das vezes são marginais, pouco estudados e ainda mal compreendidos. As suas mudanças mais visíveis envolvem novas formas de fazer agricultura e de criar diferentes modos no uso dos recursos tecnológicos e dos ativos produtivos, assim como renovadas maneiras de organização social e econômica (SCHNEIDER, et. al., 2014).

As atividades e iniciativas desse processo são consideradas parte de um novo modo de fazer agricultura, e estão espraiadas pelo espaço rural (destaca-se a agroecologia, a agregação de valor mediante a agroindustrialização, ou ainda o empreendimento de novas atividades como a produção de energia 'agrocombustíveis' e o turismo rural), sendo de fundamental importância na promoção de meios sustentáveis de desenvolvimento e na geração de qualidade de vida para um significativo contingente de famílias rurais (SCHNEIDER, et. al., 2014). São denominadas como sementes e brotos da transição, os quais:

\footnotetext{
Refere $(m)$-se a práticas e processos que são uma expressão empírica e fenomênica de uma nova forma de fazer agricultura que estão sendo construídas, em alguns casos de forma silenciosa, descontínua, mas em outros casos, de forma sistemática e com certa visibilidade pública. Essas sementes e brotos podem ser representados por alterações no modo de organização do trabalho e de produção, assim como no uso de conhecimento técnico e na forma de interação social e econômica (SCHNEIDER, et. al., 2014, p. 8).
} 
Esse processo de mudança crítica pode ser também entendido e/ou vinculado a elementos estruturais e externos que vêm acontecendo nos últimos anos e que podem estar inter-relacionados. Por exemplo, o reconhecimento presente que a agricultura familiar e camponesa vem conquistando entre diferentes organismos supranacionais e eventos internacionais ${ }^{2}$.

O desafio é analisar e entender esses processos de mudança, através dos quais certas formas sociais surgem, são transformadas e retrabalhadas na vida das pessoas. As lentes de pesquisa têm que se orientar, como proposto por Arce (2003), nas formas pelas quais os indivíduos e certos grupos alteram os processos e rumos da sua vida, terminando por se integrar a outros projetos individuais e grupais, readaptando assim às suas estratégias existentes, ou gerando a partir daí seus próprios caminhos para o câmbio social.

O arcabouço teórico-conceitual que baliza as discussões do presente trabalho se fundamenta nos aportes da Perspectiva Orientada ao Ator (POA), desenvolvida por Norman Long e Jan Douwe van der Ploeg a partir da segunda metade do século $X X$. Segundo os autores, embora muitas mudanças estruturais sejam, de fato, resultado de forças externas como a ação do Estado, do mercado e organismos multilaterais na criação e promoção de políticas internacionais pró-desenvolvimento, essas formas de intervenção somente irão afetar as oportunidades sociais e a conduta dos indivíduos na medida em que se introduzem em seus modos de vida, tomand o forma, direta ou indiretamente, nas experiências do cotidiano (LONG, 2007; LONG; PLOEG, 2011).

É necessário esclarecer que a POA não entende a chamada estrutura como um aparelho rígido e fechado, com características que têm o viés de determinar ou direcionar de fora para dentro a ação dos atores. Dita estrutura é entendida como "um auxiliar que oferece referências externas na articulação de projetos dentro da arena. Nessa direção, a noção de estrutura na POA é constituída pelo entrelaçamento dos projetos sociais dos vários atores de representação macro e micro" (COTRIM, 2013, p. 76).

Em relação às intervenções externas profundamente analisadas e criticadas por Long e Ploeg, Deponti (2007) propõe que aquilo que eles criticam em realidade são as formas de intervenção mais do que a própria intervenção, toda vez que eles se manifestam em relação àqueles modelos de intervenção prontos que são aplicados de cima para baixo, através de projetos realizados por agências de desenvolvimento que já têm objetivos definidos e esperados, e que comumente são aplicados por agentes desenvolvimentistas, como por exemplo, extensionistas.

Um processo de intervenção, qualquer seja, é complexo, toda vez que ao longo do seu percurso de aplicação este envolve uma série de reinterpretações ou transformações, além de que a realidade local muda constantemente. Esta, por sua vez, é composta por percepções culturais e interesses sociais diferentes, donde os atores envolvidos se encontram em contínuos esforços sociais e políticos,

\footnotetext{
2 Por exemplo, a Organização das Nações Unidas para a Alimentação e a Agricultura (FAO) celebrou em 2014 o Ano Internacional da Agricultura Familiar; e mais recentemente, em 2018, a Declaração dos Direitos dos Camponeses e Camponesas e de outras pessoas que trabalham nas áreas rurais foi subscrita também pela ONU (La Via Campesina, 2018).
} 
legitimando seus projetos pessoais e coletivos, não representando simplesmente um plano de ação já especificado e com resultados esperados (DEPONTI, 2007).

A noção de agência como o elemento central da ação dos atores, se refere:

"a capacidade de processar a experiência social vivida e desenhar maneiras
de lutar com a vida, ainda sob as formas mais extremas de coerção, dentro
dos limites de informação, incertezas e outras restrições, onde os atores
sociais têm capacidade de saber e capacidade de atuar" (LONG, 2007, p.
48).

A agência dos atores cobra força e emerge a partir de uma interação permanente, seja esta em redes ou contatos constantes nos quais são compartilhados ou mobilizados diversos itens como conhecimentos entre atores diferentes como agricultores, pesquisadores, extensionistas, consumidores, etc. (GAZOLLA, 2012). Mas, sempre que seja possível e/ou necessário, essa diversidade de atores irá se articular em movimentos sociais, lutas, arranjos institucionais e na construção de redes que lhes proporcionem melhores condições de vida, preços justos aos seus produtos agrícolas e maior segurança no acesso a recursos escassos (PLOEG, 2009). Esses agricultores, assim como outros atores, possuíam uma agência que não estava isolada do contexto, senão que esta era parte do substrato social necessário a partir do qual eles conseguiram construir conhecimentos e novidades junto a outros atores em uma visão própria do que seria seu desenvolvimento local (GAZOLLA, 2012).

Para o caso que nos interessa neste artigo, a geração de conhecimento e as inovações da agricultura familiar são entendidas como um processo, resultado das agências, capacidades, recursos e relações dos atores rurais que em Dom Feliciano se articularam inicialmente a partir de um processo de planejamento participativo. As inovações sócio-organizativas, a partir Triches et. al. (2014, p. 119), podem ser definidas não só como sinônimos de novos produtos e serviços, senão como renovadas formas de organização social e diversificação econômica, resinificando, alterando e adaptando intervenções governamentais, modos de organização do trabalho e de produção tradicional, através da criação de novas redes e relações sociais, que incentivam a junção de identidades locais em uma determinada área rural, sobre um exercício de disseminação de conhecimentos e da soma de esforços entre uma diversidade de atores e instituições.

Por tanto, se reconhece que os mais diversos grupos sociais no rural têm desenvolvido historicamente processos endógenos ou localmente situados de construção do conhecimento. Os agricultores (em sua acepção mais abrangente como pecuaristas, pescadores, artesãos, etc.) vêm produzindo um acumulado de conhecimento na sua relação cotidiana com o meio ambiente seja este a partir das práticas de produção agrícola ou nas formas de relacionamento comunitário (COTRIM; DAL SOGLIO, 2016).

A construção de conhecimento que tem lugar em contextos rurais é resultado de um processo de diálogo, experimentação e acúmulo de saberes. Conforme Cotrim e Dal Soglio (2016), este se edifica no tempo pelos atores comunitários, perpassando as mais diversas dimensões, práticas produtivas e até os arranjos sociais. Segundo eles, na atualidade existe uma transição para novas formas de produção de conhecimento a quais apontam para interação diferente entre os atores e o próprio 
processo, de forma que cada dia se abrem mais espaços que possibilitam a emergência de novidades desenvolvidas por agricultores e instituições relacionadas em torno às experiências para o desenvolvimento rural (COTRIM; DAL SOGLIO, 2016).

Essa transição nas formas de produção de conhecimento se atrela ao seu caráter dinâmico, que segundo Medeiros e Marques (2011), não se refere unicamente ao meio natural, senão também ao meio social em que este conhecimento é produzido, tanto pelos poderes políticos locais, as instituições de desenvolvimento e os projetos de intervenção local. As transformações e as inovações no rural são resultado tanto do reconhecimento, como da incorporação do conhecimento local no acesso às políticas públicas e aos programas governamentais, a mercados institucionais e alternativos, assim como as formas próprias de organização social que derivam na construção de dispositivos, novidades e outras inovações sociais.

Segundo alguns autores, o conceito de novidade se refere a um novo insight, uma prática ou mesmo uma nova renovada prática. Pode também ser um novo modo de fazer ou pensar, presumivelmente com potencial para promover melhorias nas rotinas existentes (PLOEG; RENTING, 2004; apud SCHNEIDER; MENEZES, 2014; COTRIM; DAL SOGLIO, 2016). No obstante, pode ser resultado também de uma ressignificação de um processo prévio, ainda se este fosse introduzido de maneira externa. Já no caso da agricultura, a produção de novidades é um processo localizado, temporal, dependente do meio e, inclusive, dos repertórios culturais nos quais a organização do trabalho está envolvida (MEDEIROS; MARQUES, 2011).

Porém, as novidades e as inovações possuem significados distintos. Para Medeiros e Marques (2011) uma novidade está associada ao conhecimento local e, por isso, é altamente limitada ao contexto local. Tanto que para Steiver e Wiskerke (2004; apud SCHNEIDER; MENESES, 2014, p. 20), "as novidades representam rupturas constantes ao longo de um processo descontinuo e imprevisível, em que mudanças, ajustes e alterações são feitas a todo o momento".

Por outro lado, já uma inovação "é a expressão do conhecimento codificado, construída primeiramente em um mundo externo da produção, e incorporado a um artefato que pode ser transposto de um local para outro" (PLOEG, et. al., 2007; apud MEDEIROS; MARQUES, 2011, p. 83). Inova-se não só nos laboratórios e universidades na forma de conhecimento científico. As agricultoras e agricultores estão o tempo todo inovando, adaptando e criando processos, conhecimentos e tecnologias alternativas. Não se inova só na forma técnica ou tecnologicamente aceitável, senão também em processos produtivos e sócio-organizativos. Portanto, as inovações, como os conhecimentos, são processos dinâmicos e nem sempre lineares, construídos socioculturalmente, donde não há só um, senão vários que são adaptados e localizados de forma temporal, espacial e sociocultural.

No caso da inovação, não se trata de algo vindo ou vinculado de fora, e nem referida a aspectos puramente econômicos, às práticas culturais e institucionais de um determinado grupo e sua rede de relações (TRICHES, et. al., 2014). O termo inovação usado por Triches et. al. (2014, p. 119), disse que "não se trata de um sinônimo apenas de novos produtos e serviços, mas sim de uma forma de diversificação econômica, da criação de novas redes e relações sociais, da junção de identidades locais em uma determinada área rural, da disseminação de conhecimentos, da soma de esforços entre atores e instituições, dentre outros aspectos". 
No entanto, para este trabalho, a produção de novidades vai além do que aquelas que se referem, segundo Schneider e Menezes (2014), a questões práticas na forma de uso de artefatos, técnicas ou recursos, senão àquelas que se transformam em um processo de inovação social e institucional. Entende-se como um exercício que possui:

\begin{abstract}
um sentido coletivo que se adentra ao espaço de organização social e política, expressando-se por intermédio de dispositivos coletivos e associativos como cooperativas, associações e demais atividades coletivas que demandam um processo de coesão social. É uma inovação social e institucional, que implica um alinhamento de interesses coletivos em torno de um objetivo de grupo que requer organização, governança e distribuição de encargos e poder (PIRAUX; BONNAL, 2011; apud SCHNEIDER; MENEZES, 2014, p. 20).
\end{abstract}

Ao final, novidades e/ou inovações são parte resultante de um processo de construção de conhecimento que desde os estratos de agricultura familiar propõem uma ideia própria de desenvolvimento rural. Este será resultado de um longo processo de experimentação e de inovação, através dos quais os atores constroem habilidades, conhecimento e confiança em si mesmos para formar seu meio ambiente de maneira a alcançar objetivos por eles estabelecidos (LONG, 2001; DEPONTI, 2007). A ideia de desenvolvimento rural qualquer que esta seja, deve estar fundamentada "no papel das associações e entidades criadas pelos próprios atores locais, mesmas que são essenciais para manter as atividades inovadoras, estabilizar as relações locais e criar novas redes, que estão sendo vistas como a maior fonte de inovação em todos os casos estudados, pelo potencial que representa para os processos de desenvolvimento rural" (DARGAN; SHUCKSMITH, 2006; apud TRICHES, et. al., 2014, p. 114).

\title{
3 Metodologia utilizada para o caso de estudo apresentado
}

O presente trabalho se encontra ancorado nos aportes de uma metodologia qualitativa3, apoiando-se por sua vez como método de pesquisa em um estudo de caso e na utilização de técnicas e ferramentas etnográficas como observação direta e participativa, entrevistas semiestruturadas e diário de campo. Decidiu-se pelo ferramental etnográfico procurando uma proximidade dos atores e a imersão no território, para identificar no nível discursivo e prático, a trajetória de eventos e ações na cotidianidade observando e registrando, questionando e confrontando depoimentos e informações. A escolha do estudo de caso como forma de encarar esta temática de pesquisa deu-se por estar baseada em "uma abordagem qualitativa na qual o investigador explora um sistema contemporâneo da vida real (um caso) ou múltiplos sistemas delimitados (casos) ao longo do tempo, por meio da colheita de dados detalhada em profundidade envolvendo múltiplas formas de investigação" (CRESWELL, 2014, p. 86).

3 Para Denzin e Lincoln (2011; apud CRESWELL, 2014), uma pesquisa qualitativa é uma atividade situada que localiza ao observador no mundo, a qual consiste num conjunto de práticas materiais interpretativas, que incluem notas de campo, entrevistas, conversas, fotografias, registros e lembretes, que ajudam a tornar representativo um mundo visível. 
Por outro lado, o uso das ferramentas de uma pesquisa etnográfica são de utilidade, pois ajudam na compreensão do ser humano no seu contexto sociocultural. A utilização dessas técnicas de pesquisa etnográfica devem ser adequadas ao objeto de estudo, seja através da utilização de questionários, entrevistas ou observação participante, além de que se exige uma efetiva participação do pesquisador no processo, em termos de observação e interação com os atores sociais (OLIVEIRA, 2013, p. 73-74).

O ponto de partida deste trabalho deu-se por meio de uma revisão documental realizada nos planos municipais de desenvolvimento e nos relatórios anuais de atividades da Emater/RS que estão disponíveis no escritório municipal em Dom Feliciano. Assim, também, foram analisados alguns outros documentos e pesquisas acadêmicas e institucionais que tiveram como alvo dito município, destacando-se, sobretudo os trabalhos de Gregolin (2010), Cotrim (2013), Deponti e Schneider (2013), e Rudnicki e Guerin (2014).

Entretanto, 11 entrevistas semiestruturadas por menção e identificação dos informantes chaves foram feitas com extensionistas da Emater, funcionários da Cooperativa Centro-Sul (Coopacs), da Secretaria Municipal de Agricultura e Desenvolvimento Rural Sustentável, assim como membros de cinco famílias agricultoras donfelicianenses. O diário de campo e as atividades de observação participante ocorreram em diversos cenários e espaços locais. Destacam-se principalmente algumas propriedades rurais de famílias agricultoras, eventos municipais como o Fórum de Agricultura Familiar 2018, a V Festa da Uva, e a Semana e o Jantar do Peixe. Houve também algumas conversas ou bate-papo mais informais que foram travados em espaços como restaurantes, negócios locais e parques públicos, pelo fato de estar presente permanentemente no território pesquisado no período compreendido de outubro de 2018 a abril de 2019.

\section{Uma breve descrição do recorte socioespacial do caso estudado e do Processo de Planejamento Participativo.}

Dom Feliciano é um município brasileiro que faz parte do Estado de Rio Grande do Sul. Localiza-se geograficamente na zona Sul, distante 170 quilômetros de Porto Alegre, capital do Estado ${ }^{4}$. Possui uma área de $260,2 \mathrm{~km}^{2}$, sendo formado por um relevo acidentado e caracterizado basicamente como um município rural que a partir de projeções realizadas pelo Instituto Brasileiro de Geografia e Estatística (IBGE) considera para 2018 uma população estimada de 15.338 pessoas, com uma densidade demográfica para 2010 de 10,60 habitantes/km² (IBGE, 2019). Os dados do Censo Demográfico de 2010 (IBGE, 2010) mostraram que a população total, naquele ano, era de 14.380 habitantes, sendo 3.334 residentes na zona urbana ( $23,2 \%$ do total) e 11.046 no meio rural $(76,8 \%$ do total).

Também segundo o Instituto, o território faz parte da microrregião de Camaquã, tendo proximidade com a região central do Estado, numa distância

4 O site web da Prefeitura Municipal de Dom Feliciano sinaliza um distancia á capital de $112.4498 \mathrm{Km}$. https://www.domfeliciano.rs.gov.br/portal/cidade/1/Dados-Gerais-Dom-Feliciano---RS. Em Dom Feliciano cerca de 90\% da população é descendente de poloneses, tendo a chegada dos seus primeiros imigrantes em 1861 quando foi criada a Colônia de São Feliciano, embora a colonização final se deu entre 1890-1891 (GREGOLIN, 2010; DEPONTI; SCHNEIDER, 2013; RUDNICKI; GUERIN, 2014). 
aproximada de 100 quilômetros de Rio Pardo, 200 de Candelária e 140 de Santa Cruz do Sul. Trata-se de um município preponderantemente rural não só pela distribuição populacional, senão também pela sua estrutura socioeconômica. De acordo com Gregolin (2010), existem aproximadamente 2.500 propriedades com menos de 50 hectares, equivalendo a $87 \%$ das propriedades classificadas como de agricultura familiar.

A cultura do tabaco (ou, "fumo") é a principal atividade em termos de fonte de renda municipal agropecuária. Em 2017, segundo IBGE (2019), o valor da produção do fumo, em valores correntes, foi de $\mathrm{R} \$ 81.688 \mathrm{mil}$, representando $79 \%$ do total do valor da produção agrícola (que foi estimado em $\mathrm{R} \$ 103.456$ mil). Para a safra 2017/18, havia uma estimativa de que 1.872 famílias estariam envolvidas na atividade (SINDITABACO, 2019). Outra das atividades agrícolas importantes junto ao fumo é a produção de milho em grão que se destaca pela quantidade produzida, valor da produção e área plantada e colhida (Tabela 1). As demais culturas, menos representativas, têm como finalidade principal a comercialização, ou têm esta ação para seu excedente.

Tabela 1. Principais culturas agrícolas em Dom Feliciano e suas características produtivas 2016-2017

\begin{tabular}{|c|c|c|c|c|c|}
\hline Cultivo & $\begin{array}{l}\text { Quantidade } \\
\text { produzida } \\
\text { (Toneladas) }\end{array}$ & $\begin{array}{c}\text { Valor da } \\
\text { produção (x } \\
1000 \text { R\$) }\end{array}$ & $\begin{array}{c}\text { Área } \\
\text { plantada } \\
(\mathrm{Ha})\end{array}$ & $\begin{array}{c}\text { Área } \\
\text { colhida } \\
\text { (Ha) }\end{array}$ & $\begin{array}{l}\text { Rendimento } \\
\text { médio (kg/ha) }\end{array}$ \\
\hline Arroz com casca & 187 & 148 & 35 & 35 & 5343 \\
\hline Batata doce & 3220 & 2381 & 230 & 230 & 14000 \\
\hline Batata Inglesa & 136 & 199 & 60 & 60 & 2267 \\
\hline Feijão grão & 205 & 804 & 305 & 305 & 672 \\
\hline Fumo folha & 12150 & 81688 & 6000 & 6000 & 2025 \\
\hline Mandioca & 1980 & 1708 & 180 & 180 & 11000 \\
\hline Melancia & 4350 & 2309 & 290 & 290 & 15000 \\
\hline Milho grão & 22500 & 10416 & 5000 & 5000 & 4500 \\
\hline Soja & 1620 & 1761 & 600 & 600 & 2700 \\
\hline
\end{tabular}

Fonte: IBGE (2019).

A hegemonia da fumicultura começou a ser verificada a partir do processo de modernização agrícola. Entre as décadas de 1970 e 80 o cultivo de tabaco chegou a Dom Feliciano por ação de mediadores sociais que difundiram a tecnologia e insumos modernos, com direcionamento para uma agricultura empresarial (COTRIM, 2013). No entanto, o caráter hegemônico do tabaco, situação municipal donfelicianense, segundo Deponti e Schneider (2013, p. 179):

não destoa da metade sul, pois o município apresenta baixa industrialização, desenvolvimento econômico e social aquém das 
condições mínimas. O espaço rural apresenta basicamente pequenas propriedades na Encosta da Serra do Sudeste, em que há predominância da cultura do fumo, e médias e grandes propriedades na Serra do Sudeste, em que predomina a pecuária extensiva.

Gregolin (2010, p. 29) ressalta que apesar das contribuições econômicas realizadas ao PIB municipal pela fumicultura, existiam preocupações econômicas e sociais que se tornariam um desafio maior para o município, junto a outras variáveis associadas como por exemplo; a saúde, educação e meio ambiente. Nesse sentido, no ano 2000, um trabalho do jornal gaúcho Zero Hora5, intitulado Pobreza em Dom Feliciano, e citado pela autora, apresentou uma complexa situação municipal. Segundo essa reportagem a precariedade das condições locais são visíveis antes de se chegar ao município, donde pelo menos 40 quilômetros de estrada de chão batido isolam Dom Feliciano do asfalto mais próximo.

De acordo com essa fonte, acrescentava-se que apenas 5,7\% das crianças entre zero e seis frequentavam a pré-escola e nenhuma estava matriculada em creches, além de que o município contava com uma verba federal de apenas $\mathrm{R} \$ 900$ mensais para um programa de complementação alimentar, suficiente para atender 60 crianças. Essa situação reforçava a posição do município no ranking da pobreza no Rio Grande do Sul, onde ocupava a última posição, conforme acima mencionado.

Outras medições como o Índice de Desenvolvimento Socioeconômico, calculado pela Fundação de Economia e Estatística (FEE/RS), registraram para 2012 um resultado igual a 0,559, colocando o município na $495^{\text {a }}$ posição, entre os 496 municípios do Estado do Rio Grande do Sul. Este dado alia-se ao dado do Atlas Brasil (2019), que apontou, para 2010, que 32,11\% da sua população estava em situação de pobreza extrema, ou de pobreza.

Embora o pouco favorável panorama apresentado, no meio desta conjuntura de início do século XXI, uma gênese social que transcenderia a temporalidade e a espacialidade começava por ser vivenciada em Dom Feliciano. Esta mudança é interpretada nas seções a seguir.

\section{1 “Os inícios" de um processo de Planejamento Participativo Regional}

A partir do ano 2000 na região Centro-Sul de Rio Grande do Sul, a construção de um processo de Planejamento Participativo Regional (PPR) começa a ser dinamizado envolvendo alguns atores - entre eles, agricultores familiares -, desde um nível comunitário, passando pelo estrato municipal, até chegar ao nível territorial (COTRIM, 2013), no que seria o desenho de uma nova proposta de desenvolvimento rural. Neste exercício, a Associação Riograndense de Empreendimentos de Assistência Técnica e Extensão Rural (EMATER-RS) teve papel relevante, pois segundo Cotrim (2013, p. 122), ao passar por uma revisão das "ações extensionistas até então desenvolvidas pelos seus técnicos, onde o comum denominador havia sido que as interfaces com agricultores estavam baseadas principalmente nos formatos tradicionais do tipo top-down característicos da modernização da agricultura", se

\footnotetext{
5 Essa matéria pode ser consultada fisicamente como parte de arquivo documental em possessão do escritório municipal da Emater em Dom Feliciano/RS.
} 
redemocratizou para incorporar a participação local, envolvendo outros atores, sobretudo não institucionais.

Assim, a partir da ideia de uma reconstrução da política institucional de Emater, abriu-se espaço para a participação dos agricultores no processo de Diagnóstico e Planejamento Municipal e Territorial. A participação de outros atores além dos agricultores, como foram os Sindicatos Rurais, as Organizações Não Governamentais (ONG's), e as Organizações Governamentais do âmbito estadual, também foram parte desse processo de Planejamento Participativo Regional (PPR) (COTRIM, 2013). Apesar do desejo de transição institucional, o processo não foi simples, nem rápido. De toda forma, a experiência acumulada e testada em metodologias participativas em torno de outros projetos, foi decisiva para as ações da Emater/RS 6 .

Além do anterior, outro dos fatores que catalisaram e promoveram esta forma de participação social diferente foram a conjuntura política dos anos 1990 e início dos anos 2000 que era vivenciada no estado de Rio Grande do Sul. Conforme elencado por Cotrim (2013), o governo de Olívio Dutra e do Partido dos Trabalhadores (PT) promovia através da proposta de Orçamentos Participativos uma visão de desenvolvimento baseada num processo de planejamento participativo que visava a se estender no nível estadual.

Após permanecer ativo por um período de onze anos (2000 a 2011), o Planejamento Participativo Regional permitiu na região Centro Sul a realização de dez fóruns territoriais que registraram uma participação média de 250 pessoas por edição (COTRIM, 2013). A partir de 2010, como resultado desse processo de construção social, a região Centro-Sul passou a se considerar um Território Rural e a se constituir como um Conselho de Desenvolvimento Territorial (CODETER). Foi na esfera da sua própria experiência de participação social que a proposta inicial de um processo participativo a nível municipal foi levada para Dom Feliciano pelos articuladores da Emater/RS que trabalham no âmbito territorial (COTRIM, 2013).

\subsection{A gênese de um processo de Planejamento Participativo Municipal (PPM) em Dom Feliciano/RS}

O Planejamento Participativo em Dom Feliciano é apresentado e começa a ser desenvolvido em 2001, a partir de proposta realizada pelos articuladores territoriais de Emater. Uma equipe municipal mais ampla de articuladores esteve composta por integrantes desta mesma organização, em conjunto com funcionários da Secretaria Municipal de Agricultura e do Sindicato dos Trabalhadores Rurais. Esta equipe foi a responsável pelo desenho de uma estratégia teórico-metodológica do PPM a qual estava integrada por: i) formação básica do método participativo; ii) estratégia geral de sensibilização para reuniões; e, iii) proposta de divisão municipal em 12 locais (COTRIM, 2013).

Conforme Maffini e Lemos (2001), o planejamento participativo no seu nível municipal teve na primeira etapa a realização efetiva de doze reuniões comunitárias

\footnotetext{
${ }^{6}$ Desde o início da década de 1990, o método participativo como tal e a participação das comunidades rurais vinham sendo estudados e testados pelos articuladores territoriais da Emater-RS em projetos tutelados pela GTZ sobretudo na utilização de ferramentas participativas na mediação comunitária (COTRIM, 2013, p. 121-122).
} 
para igual número de comunidades. O objetivo desses encontros foi a discussão das questões em torno do desenvolvimento comunitário e da sistematização das principais demandas e necessidades coletivas a serem levadas a um grupo consultivo permanente (fórum). Além disso, outra das finalidades era eleger um ator rural a nível comunitário para que pudesse participar como representante no Fórum Municipal de Dom Feliciano.

Após as reuniões em cada comunidade, a segunda etapa constituiu-se na realização do citado Fórum Municipal que tinha como objetivo inicial a construção coletiva de um diagnóstico do município (COTRIM, 2013). Empregando ferramentas participativas, primeiramente foram realizadas e debatidas atividades em torno a um resgate histórico do município, ou também chamado de Itinerário de Desenvolvimento Municipal7. Outra atividade foi uma leitura de paisagem coletiva ao longo do município ${ }^{8}$, através da qual foi elaborado um mapa com a divisão municipal de regiões homogêneas, mediante uma sistematização das suas semelhanças e diferenças (MAFFINI; LEMOS, 2001). A terceira atividade do Fórum girou em torno da discussão e da sistematização das prioridades levantadas ao longo das reuniões comunitárias, para depois selecionar aquelas que a critério do coletivo foram prioritárias no âmbito municipal ${ }^{9}$ (Ver Figura 1).

A obtenção do ranking de prioridades apontou na direção de construir e dar continuidade aos trabalhos futuros em duas escalas, uma no nível regional e outra no nível local. As demandas econômicas, sociais e ambientais de Dom Feliciano foram levadas ao Fórum Territorial Centro-Sul por representantes municipais (Prefeito, funcionários públicos, extensionistas da Emater, representantes comunitários) na ideia que fossem fontes para a construção coletiva do Plano Estratégico Regional de Desenvolvimento Sustentável (BRASIL, 2009; apud COTRIM, 2013). Esse ranking com a priorização de demandas seria o insumo principal para a criação do Plano Estratégico Municipal de Desenvolvimento Rural (PMDR) (MAFFINI; LEMOS; 2001). A figura a seguir sumaria resultados das reuniões do Fórum Municipal de Dom FelicianoRS.

\footnotetext{
7 A periodização em questão abrangeu quatro períodos históricos: i) Imigração 1872-1924; ii) Colonização 19251970; iii) Desenvolvimento 1971-1992; iv) Estagnação 1993-2001. Cada uma destas etapas descreveu as características presentes, os atores e fatores que participaram desse desenvolvimento histórico, e finalmente o reflexo de cada fase (MAFFINI; LEMOS, 2001).

8 As principais dimensões que foram consideradas para a leitura da paisagem foram: as diferenças existentes entre os agroecossistemas, os sistemas de cultivo e criação, as referências étnicas, a infraestrutura instalada, o destino da produção, entre outros elementos (MAFFINI; LEMOS, 2001).

9 Usando como técnica de apoio tarjetas com visualização móvel foi elaborado e negociado um ranking de prioridades onde estavam consideradas as principais demandas e as necessidades municipais nos aspectos econômicos, sociais e ambientais (MAFFINI, LEMOS; 2001), que deveriam ser atendidas no curto prazo.
} 


\section{Figura 1. Principais demandas obtidas das reuniões comunitárias e Fórum Municipal-Dom Feliciano (2001)}

\section{Nível comunitário}

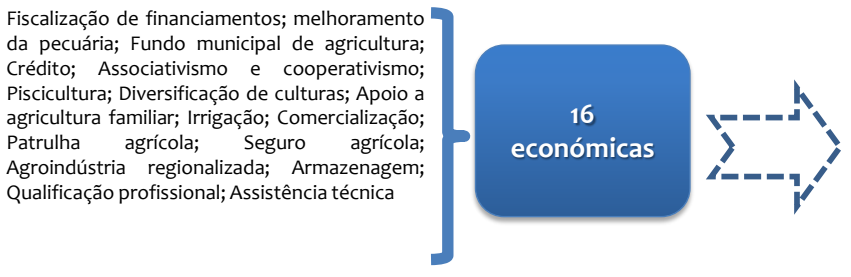

Poços artesianos; Aumento da rede elétrica; Aumento da tensão da rede elétrica; Escola Agrícola; Incentivo ao esporte; Quadra de esporte; Melhoria de transporte escolar; Emprego para mulheres; Transporte coletivo; Material escolar; Plantão médico 24 horas; Ensino supletivo; Melhoramento das escolas; Escola até 8va. serie no interior; Melhoria no atendimento médico; Postos de saúde no interior; Transporte emergencial; Atendimento dentário; Farmácia básica mais medicamentos; Qualificação médica; Merenda escolar; Quaticaç
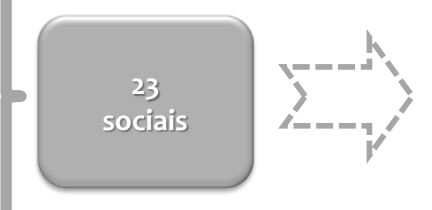

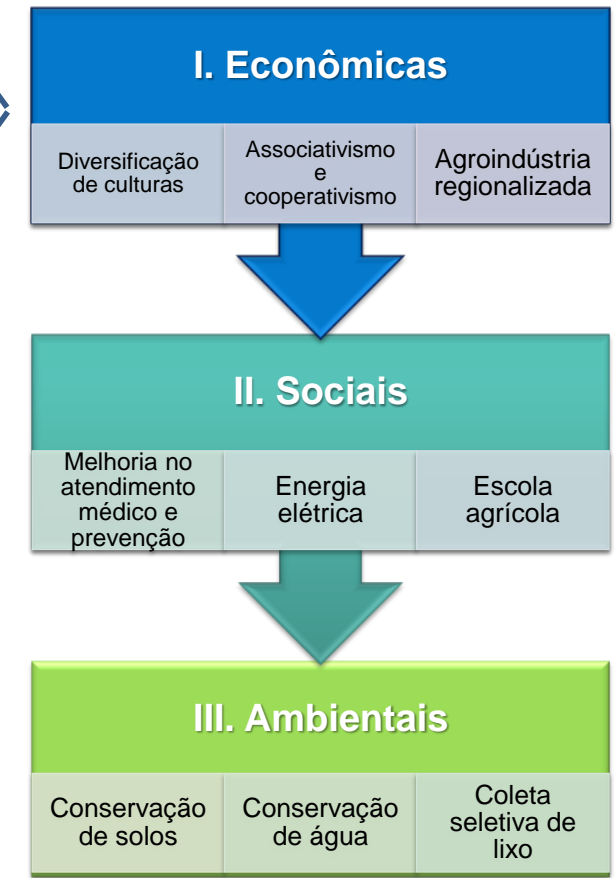

Nível municipal

Fonte: elaboração própria a partir de Maffini e Lemos (2001).

\section{0 processo de inovação social e institucional em Dom Feliciano: A materialização do conhecimento e as inovações da agricultura familiar.}

Vinte anos depois, ao longo das duas primeiras décadas do século XXI, se o olhar estiver orientado só há Indicadores Econômicos, Dom Feliciano teria avançado pouco. No entanto, existem outros eventos e situações em torno de uma trajetória de longo prazo e com características e dimensões que possuem um viés mais qualitativo. A semente dessa transição se deu através da proposta do planejamento participativo.

A primeira tarefa foi a conformação de uma equipe de articuladores que estaria composta por técnicos da Emater, funcionários da Prefeitura Municipal, assim como do Sindicato de Trabalhadores Rurais, os quais já estavam afinados com as premissas de um trabalho coletivo e participativo ${ }^{10}$. Trata-se, portanto, da figura prévia de um Conselho Municipal de Desenvolvimento Rural, o mesmo que a posteriori seria o espaço no âmbito municipal no qual os atores apresentariam e defenderiam alguns dos projetos que hoje em dia vêm se materializando, no que é

10 A tarefa dessa equipe articuladora, como sinalizada por Cotrim (2013), haveria sido a elaboração de uma estratégia teórico-metodológica e operativa inicial em que se basearia primeiramente no trabalho de sensibilização comunitária para levar a cabo as reuniões com as famílias agricultoras das diversas comunidades, assim como para fazer uma divisão do espaço municipal em doze locais representativos, e por último a operacionalização dos encontros comunitários. 
por eles considerada uma ideia de desenvolvimento. Esta é entendida como um processo de melhora da qualidade de vida baseado sobre a diversificação produtiva de atividades alternativas ao cultivo de tabaco, produzindo alimentos de qualidade e gerando rendas complementarias, porém preservando o meio ambiente, e visando a permanência da juventude rural (DIÁRIO DE CAMPO, 2019).

Uma das primeiras reivindicações das comunidades rurais foi a representação direta de membros de famílias agricultoras no interior do CMDR já que até então não faziam parte dele, pois como em alguns outros destes espaços nos municípios da região Centro Sul, os Conselhos estavam conformados apenas por representantes das instituições agrárias como sindicatos rurais, bancos e prefeitura municipal (COTRIM, 2013). Essa representação se deu depois de reuniões comunitárias, quando os representantes passaram a ser oficializados pela Prefeitura Municipal e se lhes reconheceu como membros do CMDR. Além disso, a criação de associações comunitárias que vinha sendo realizada teve continuidade e se reforçou, resultando na formação e no registro posterior de inúmeras associações, donde cada uma destas requereu uma vaga para participação efetiva junto aos outros membros do CMDR (COTRIM, 2013, p. 130). Manifestações dos entrevistados ilustram este movimento:

\begin{abstract}
começamos a criar associações lá pelos anos 1999-2000. A ideia foi pensando em se organizar (sic!) como produtores para a compra de insumos, principalmente para o tabaco, e já também para um pensamento conjunto de como produzir alimentos, porque tinha lá aquele produtor que produzia porco, milho, feijão, leite, batata; mas que não tinha nada organizado para vender. Por isso foi que criamos as associações (Entrevistado 1).

Isto começou em 2001 com o projeto desenvolvido no escritório regional da Emater em Porto Alegre, que depois foi trazido a Dom Feliciano para realizar um planejamento estratégico no nível de diagnostico, de ações, de levantamento de demandas, encaminhamentos e a priorização dessas atividades a serem promovidas para o desenvolvimento das famílias do município e da região (Entrevistado 2).
\end{abstract}

Existem dois elementos importantes que atualmente podem ser observados em Dom Feliciano, a partir das atividades e eventos dinamizados pelos atores locais. A construção de conhecimento coletivo que se deu em torno das reuniões comunitárias e no Fórum Municipal, onde os ditos exercícios resultaram na reconstrução coletiva da memória histórica do município ${ }^{11}$, permitindo que a população local tivesse uma identificação para com o processo e a trajetória atual que estão vivenciando. O segundo elemento, também reconhecido pelos atores, se refere à criação e ao incremento no número de associações comunitárias. Em 2001, segundo Maffini e Lemos (2001), existiam 18, que depois se incrementaram para 23, em 2005, e já em 2019 existem 35.

As associações fazem partem do Conselho aonde se tem onze representantes. Por núcleo de três regiões cada uma está representada no Conselho porque não tinha como colocar todas. Hoje são 35 associações. Aumentou para 35 as que estão organizadas. Porque se consideramos as

11 Itinerário de Desenvolvimento Municipal e a Identificação dos Principais Sistemas Agrários (MAFFINI; LEMOS, 2001). 
que não estão organizadas, seriam mais, só que nos temos que ver aquelas que estão com registro na Junta Comercial, que fazem o mínimo de contabilidade, que fazem a certificação digital obrigada por Lei a fazer o ano todo. Assim, nos teríamos 35 (Entrevistado 1).

\subsection{O Plano Municipal de Desenvolvimento como dispositivo sócio-organizativo para materializar o conhecimento e as inovações.}

Com a incorporação dos representantes comunitários ao CMDR se deu a possibilidade de confeccionar o Plano Estratégico Municipal de Desenvolvimento Rural. Este se tornou um balizador para a constituição das políticas públicas municipais que não eram somente de responsabilidade da Prefeitura, senão também da sociedade civil e setor empresarial, de forma que ação conjunta terminou por se vincular através dos Planos Operativos (PO). O dito processo de planejamento conjunto a nível municipal catalisou a participação dos atores comunitários da agricultura familiar em torno dos espaços de construção de conhecimento e inovações em curso (MAFFINI; LEMOS, 2001; apud COTRIM, 2013).

Ao longo do percurso recorrido em Dom Feliciano, um dos resultados visíveis tem sido a ampliação das capacidades individuais e coletivas, onde alguns atores, ao tempo que ampliam sua formação técnica em torno do processo e nas instituições por eles criadas, fortalecem o acompanhamento desse processo. A manifestação do Entrevistado 3 e a afirmação de Cotrim (2013) expressam esta particular dinâmica de inovação:

\footnotetext{
Antes, eu fazia parte das associações. Formei uma associação lá na localidade onde eu moro na Colônia Nova. Depois na época eu era presidente do Conselho de Agricultura e a gente também formou a Associação de Piscicultura. Participei na formação da cooperativa que ainda existe hoje, que seria a Coopacs. Tudo sempre na busca de novas alternativas. Embora, antes de tudo isso, trabalhei na cooperativa de crédito (Entrevistado 3).
}

Os articuladores da prefeitura municipal que criaram a proposta do Fórum da Agricultura Familiar ocupavam no início do PPR, em 2001, espaço no CMDR como delegados do Orçamento Participativo e representantes comunitários, estando apropriados das discussões sobre a diversificação de cultivos (COTRIM, 2013, p. 132).

Além da formação de recursos humanos e da expansão do capital social, tanto individual e coletivo, como apresentado anteriormente, outras ações sócioorganizativas na figura de eventos municipais têm sido empreendidas e algumas outras têm tido continuidade. Esses eventos cumprem diferentes funções, dentre as quais podem ser destacados a continuidade das linhas gerais e específicas do Plano Municipal de Desenvolvimento. Destaca-se que a maior demanda de diálogos e debates apresentada nestes espaços, se encontra na busca por alternativas produtivas, principalmente, para que as famílias possam diversificar suas propriedades, reduzindo assim a "dependência" para com a produção de tabaco. Outro objetivo dos eventos é que novos atores possam interagir e se apropriar dos espaços gradualmente conquistados, como uma forma de promoção social, assim como de difusão a nível regional daquilo que vem sendo construído em Dom Feliciano. 
Em torno do dispositivo do CMDR vem sendo discutidos e avaliados os possíveis resultados que se atingiram através do planejamento que se realiza anualmente, assim como da montagem do plano para o período seguinte, que basicamente é colocar em prática o PMDR já existente com os acréscimos que vão sendo identificados (COTRIM, 2013). Isso fica evidente na exposição do Entrevistado 2, a seguir:

É um trabalho que vem se desenvolvendo ao longo dos anos, mas a gente vem trabalhando a partir aquele primeiro levantamento, daquele diagnóstico aonde a gente apontou as primeiras demandas e a gente vem tentando, desenvolvendo isso ligado às organizações locais, ao próprio poder publico, às parceiras, às organizações, aos sindicatos, às cooperativas. Porque lá no início aqui na região não era forte essa questão da organização dos produtores (Entrevistado 2).

A figura 2 ressalta o percurso histórico na construção de conhecimento e inovações no município, destacando pelos seus habitantes quais haveriam sido os dispositivos, espaços e eventos que alicerçam a ideia de uma trajetória de desenvolvimento. O Fórum de Agricultura Familiar é possivelmente um desses espaços com maior destaque.

Com o início de uma nova gestão da prefeitura municipal de Dom Feliciano, a partir de 2009, outra dinâmica de ações toma forma. Um novo espaço de construção coletiva se configura no processo. O Fórum de Agricultura Familiar se constituiu como um momento anual de amplo debate entre os atores de Dom Feliciano, que foi proposto pelos articuladores municipais da prefeitura. Esse é uma iniciativa de apresentação de um conjunto de alternativas à lavoura do tabaco, e a promoção do debate dos limites e vantagens de cada ideia (COTRIM, 2013). 
Figura 2. Linha do tempo na geração de conhecimento e inovações sociais em Dom Feliciano 2000-2019

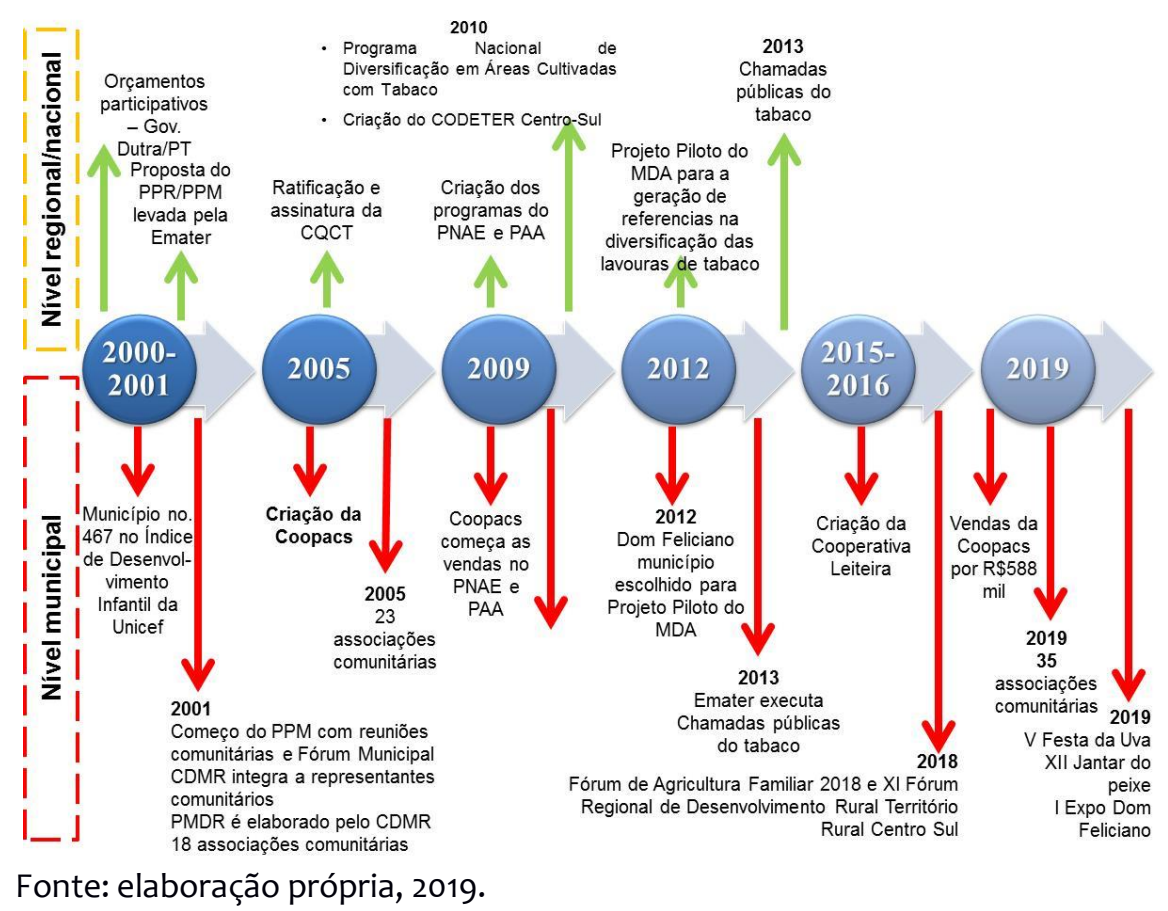

Pelo que foi observado nos diferentes espaços e eventos, a preocupação por encontrar alternativas produtivas à cultura de tabaco tem sido de algum modo o principal catalisador das dinâmicas sociais e organizativas no município, mas também no nível regional. O Fórum de Agricultura Familiar 2018 e XI Fórum Regional de Desenvolvimento Rural Território Rural Centro-Sul (ambos celebrados em torno do mesmo evento), com a participação de dez municípios diferentes, foi aberto destacando a importância e o papel que teria uma política pública para o desenvolvimento rural, em torno do qual se pudesse incorporar elementos relacionados à diversificação do cultivo de tabaco pelas consequências da Convenção Quadro para o Controle do Tabaco (CQCT) ${ }^{12}$.

Ao longo dos dois dias em que se realizou esse evento, os pronunciamentos se concentraram nas opções produtivas a serem buscadas para a diversificação das lavouras fumageiras tanto no nível municipal como regional. Os atores donfelicianenses -agricultores familiares, mulheres e jovens rurais, extensionistas da Emater e funcionários públicos- apresentaram as experiências que vêm sendo construídas em torno de projetos das famílias agricultoras que estão diversificando em opções produtivas. Se bem reconheceram o desenvolvimento de culturas alternativas como hortifrutigranjeiros, viticultura, avicultura colonial, criação de peixe, gado leiteiro e de corte, produção olericola, ovinocultura, etc.; destacaram

12 A CQCT é o primeiro acordo mundial de saúde que como instrumento jurídico e como um marco de políticas públicas de caráter internacional, visa a redução da mortalidade e morbidez planetária atribuíveis ao tabagismo. O Brasil foi o responsável da sua elaboração e negociação, assim como um dos aproximadamente 170 países signatários (MENGEL, 2011; DE DIOS; THIES, 2018). 
também que ainda há muito por fazer. Não obstante, foi elencado que essas experiências estão atreladas e ligadas fortemente a eventos como o Fórum que servem para alicercearam e manter a algumas das inovações em Dom Feliciano, principalmente a questão da Cooperativa local, as vendas nos mercados institucionais e a fábrica de suco.

\title{
5.2 A Cooperativa Agropecuária Centro-Sul (Coopacs) como materialização e articulação das demandas comunitárias.
}

A Cooperativa Agropecuária Centro-Sul (Coopacs) pode ser considerada a materialização tanto do movimento na busca de diversificação da fumicultura, como resultado também da continuidade a uma das principais demandas econômicas em torno do processo de Planejamento Participativo Municipal. O dia 19 de outubro de 2005 nasceu a Coopacs, "com a intenção de contribuir para a diversificação produtiva das unidades de produção familiar, em uma região de grande dependência em relação à produção de tabaco de estufa para venda à indústria" (QUADROS, 2018, p. 2). Um dos seus fundadores (Entrevistado 1) ressalta, por seu turno, que não haveria sido a formação da cooperativa, nem o desenvolvimento da mesma.

\begin{abstract}
O trabalho começou já dentro das associações, aí que surgiu a ideia de criar a cooperativa. Quando estavam as discussões da CQCT no Brasil, nós estávamos já com a comissão de pré-formação da cooperativa. Depois de alguns dois ou três anos que nós criamos associações comunitárias, nós reparamos que elas não tinham capacidade de vender. Foi aí que nós paramos, participamos de reuniões, viajamos e conhecemos outras estruturas porque queríamos saber como comercializar, já que as associações não tinham poder comercial (Entrevistado 1).
\end{abstract}

A unificação de 23 associações comunitárias resultou na formação a Coopacs, com o objetivo de que fosse uma cooperativa de produção voltada ao escoamento da produção de alimentos dos agricultores de Dom Feliciano, que no começo se desenvolveu apenas com o trabalho de 25 sócios e os presidentes das associações comunitárias (COTRIM, 2013). Até 2013, a Coopacs já possuía 240 associados. No entanto, continua se expandindo, tanto nas atividades realizadas, como na quantidade de sócios.

Em 2019 são 370 pessoas associadas de aproximadamente 250 famílias. Embora a gente trabalha com apenas 20 famílias de forma constante e permanente, bem articuladas. Elas produzem para nós uva, batata-doce, cebola, alface, repolho, tomate, batata-inglesa, pimentão, cenoura, couve flor, couve folha, mel, banana, laranja, vergamota, brócolis, chuchu, moranga cabotiá, feijão, milho verde, espinafre, beterraba, aipim, etc. Com as outras famílias, o problema é que elas não conseguem se desvincular do tabaco (Entrevistado 1).

Segundo Quadros (2018), ao longo da existência da cooperativa, esta vem atuando no que seriam duas grandes atividades, i) a organização de compras para seus associados como sementes, mudas, fertilizantes, alevinos, etc.; e, ii) as vendas da produção de alimentos, como olerícolas, grãos, frutíferas, sobretudo das famílias agricultoras que são sócias. Conforme a mesma autora é "a partir de 2009, com a 
criação dos mercados institucionais como Programa Nacional de Alimentação Escolar (PNAE), e o Programa de Aquisição de Alimentos (PAA), que a organização mudou o seu foco para a venda da produção de seus associados, crescendo significativamente" (QUADROS, 2018, p. 2-5).

A Coopacs vem conquistando espaços em outros mercados, diferentes daqueles que participava inicialmente. Mas também tem construído alianças estratégicas com outros atores e organizações. Por exemplo, a Cooperativa Agropecuária do município de Sertão Santana, através da qual beneficia a produção donfelicianense de uva, mediante a estrutura produtiva para a fabricação de suco de uva integral. Como parte dessa agregação de valor, tem sido possível que a Coopacs participe em Dom Feliciano do PAA e do PNAE, assim como no município de Amaral Ferrador do PNAE (QUADROS, 2018). Foram os mercados institucionais das compras governamentais e de alimentação escolar que criaram uma janela de oportunidade que até hoje continua sendo aproveitada.

\begin{abstract}
Aproveitamo-nos da Lei [de compras públicas da Agricultura Familiar]. Ela nos ajudou por que o 30\% no mínimo tem que ser de agricultura familiar. Aqui em Dom Feliciano nós sempre pegamos tudo o que fosse de licitação para o agricultor, chegando a valores de $\mathrm{R} \$ 180-190$ mil com proposta de passar disso. A gente já ganhou licitações nos municípios de Cristal, Amaral Ferrador e Encruzilhada do Sul. Embora no início a gente começou comercializando apenas $\mathrm{R} \$ 9,000.00$ no modo de pregão. Para poder vender, tínhamos que baixar uns centavos para vender cebolas, porque diante dos atacadões dos municípios de Caxias do Sul, de Pelotas, eles nos arrebentavam (Entrevistado 1).
\end{abstract}

Atualmente, as vendas realizadas através dos principais canais de comercialização dos alimentos produzidos por seus associados representaram um montante aproximado de $\mathrm{R} \$ 588,000.00$ para a safra 2018-2019, conforme a descrição de um funcionário da Coopacs.

Tabela 2. Principais mercados e o montante de recursos a partir das vendas da Coopacs 2018-2019

\begin{tabular}{|lcc|}
\hline \multicolumn{1}{|c}{ Tipo de mercado } & Valor da venda & Porcentagem \\
\hline PNAE & $R \$ 310,000.00$ & $53 \%$ \\
\hline PAA & $R \$ 180,000.00$ & $31 \%$ \\
\hline CONAB e outros varejos & $R \$ 98,000.00$ & $16 \%$ \\
\hline Feirinha direta na Coopacs & N.D. & - \\
\hline
\end{tabular}

Fonte: Coopacs (2019).

\title{
6 Reflexões finais no modo de refletir sobre os desafios futuros em Dom Feliciano
}

Dom Feliciano não é o mesmo que vinte anos atrás. Se bem os índices e medições quantitativas do desenvolvimento pouco refletem esse avanço, o diferencial pode ser encontrado de forma qualitativa, organizativa e sociocultural dos processos e ações que estão em curso. O papel de diversos atores, entre eles da 
agricultura familiar, mediante sua capacidade de agência e as redes de ação que têm estabelecido entre o poder público e privado, vem sendo importantes na construção de conhecimento e de inovações sociais a partir da emergência de dispositivos como o Conselho e o Plano Municipal de Desenvolvimento Rural. Já as inovações sócioorganizativas aqui consideradas, emanadas destes dispositivos, se referem a novas formas de organização social e de diversificação econômica que visam a criação de formas diferentes de comercializar e de oferecer alternativas socioprodutivas, mediante a estruturação melhor da produção, desde as propriedades familiares, através da constituição de inovações como a Coopacs. Nesse sentido, hoje em dia existem quatro famílias que diversificaram totalmente suas propriedades e abandonaram a cultura do tabaco, focando na produção de alimentos e na agregação de valor por meio de alguns outros produtos, como mel e doces. Podem representar muito pouco essas quatro famílias, não obstante, para a população donfelicianense é o começo de outro processo, para um diferente futuro. Metaforicamente, as sementes ou brotos que elas representam, vão produzir frutos ou novos brotos no longo prazo.

O município vem mudando, ainda que seja em um ritmo de crescimento lento e próprio que há sido determinado pela diversidade de atores. Outras inovações sócio-organizativas que também poder ser destacadas se referem aos Fórum Municipal e Regional da Agricultura Familiar, da I Expo Dom Feliciano, da V Festa da Uva e da Semana e Jantar do Peixe, os quais dão força e suporte a um tecido social que permite valorizar e se apropriar dos resultados conquistados de um exercício de planejamento democrático através da junção de identidades e da soma de esforços, alterando e resinificando processos induzidos externamente ao território. É inegável que a experiência donfelicianense na construção coletiva de conhecimento e das inovações sócio-organizativas já destacadas, esta apoiada ou reforçada por uma estrutura externa de ações de políticas de desenvolvimento rural e/ou territorial que é influenciada reciprocamente. Não obstante tem que se reconhecer e dar valor que a mudança social hoje em curso em Dom Feliciano foi uma janela de oportunidade aproveitada pela diversidade de atores e organizações, tanto internos como externos, que se vincularam mutuamente para a reconstrução da estrutura.

Existem também outras figuras inovativas construídas ao longo do caminho percorrido, que embora não conseguiram ainda avançar, mas que se tornam um desafio futuro segundo os atores locais, seriam a Cooperativa de leite, a reabertura da fábrica de sucos que foi inaugurada em 2016, a padaria local, além da instrumentalização final do Sistema de Inspeção Municipal, a continuidade do projeto de educação agroecológica promovido pela EJR, os conselhos municipais de saúde, e de meio ambiente, entre alguns outros. Assim mesmo, o município vem avançando na diversificação de opções produtivas em torno da cultura de tabaco, sobretudo destacando aquelas que estão em andamento como a olericultura com a empresa Costa Doce, a produção de laranja orgânica com a empresa Ecocitrus, e a batata-doce que vem se constituindo num cultivo com potencial para ser referente do município, já que sua qualidade tem lhe permitido aceso e permanência em mercados como a CONAB.

Em suma, o processo de construção de conhecimento e de inovações sociais que está em curso em Dom Feliciano se caracteriza principalmente pelo protagonismo e apropriação por parte dos atores em torno da categoria de 
agricultura familiar. Ao ser o segmento mais representativo no nível municipal, seus protagonistas imprimem e determinam através dos diversos espaços de discussão e negociação o tempo e o ritmo em que o processo deve caminhar. A difusão de experiências como a aqui relatada é muito importante para a região Centro-Sul, porque fortalece e gera novas dinâmicas locais entre atores e organizações de diferentes níveis, vinculando-os através de redes de ação por meio das quais podem se inserir e se articular economicamente e socialmente, tanto a outras regiões como a diversos atores, no objetivo de construir um processo participativo e autônomo de desenvolvimento.

\section{Agradecimentos}

Principalmente às famílias agricultoras as quais nos permitiram a realização de vivências nas suas propriedades, para fazer diversas atividades como observação direta, participante, entrevistas semiestruturadas e um diário de campo bem extenso. Assim mesmo, agradecemos desde já aos funcionários da Cooperativa Agropecuária Centro-Sul (Coopacs), do escritório municipal da Associação Riograndense de Empreendimentos de Assistência Técnica e Extensão Rural (EmaterRS), finalmente à Secretaria Municipal de Agricultura e Desenvolvimento Rural; todos eles do município de Dom Feliciano/RS. Agradecimentos também ao Conselho Nacional de Desenvolvimento Científico e Tecnológico (CNPq).

\section{REFERÊNCIAS}

ARCE, A. Re-approaching Social Development: a field of action between social life and policy processes. Journal of International Development. V. 15, n. 7, p. 845-861, Set. 2003.

ATLAS do Desenvolvimento Humano. PNUD; Fundação João Pinheiro; IPEA (orgs.). Índice de Desenvolvimento Humano 2010. Disponível em http://www.atlasbrasil.org.br/2013/ranking. Acesso em 28 de agosto de 2019.

COTRIM, Décio Souza; DAL SOGLIO, Fábio Kessler. Construção do Conhecimento Agroecológico: Problematizando a noção. Revista Brasileira de Agroecologia, [S.I.], v. 11, n. 3, sep. 2016. ISSN 1980-9735. Disponível em: <http://revistas.abaagroecologia.org.br/index.php/rbagroecologia/article/view/16772>. Acesso em 28 de agosto de 2019.

COTRIM, D. $O$ estudo da participação na interface dos atores na arena de construção do conhecimento agroecológico. 201 3. 264p. Tese (Doutorado em Desenvolvimento Rural) - Universidade Federal do Rio Grande do Sul, Porto Alegre, 2013.

CRESWELL JW. Investigação qualitativa e projeto de pesquisa. Escolhendo entre cinco abordagens. São Paulo: Penso Editora LTDA, 2014. 
DE DIOS, D.; THIES, V. "análise comparativa da implementação da Convenção Quadro para o Controle do Tabaco no México e no Brasil”. In:. OLIVEIRA, M. et. al. (ORG.) Saúde coletiva, desenvolvimento e (in)sustentabilidade no rural. Porto Alegre. Editora da UFRGS, 2018.

DEPONTI, C. M.; SCHNEIDER, S. A extensão rural e a diversificação produtiva da agricultura familiar em áreas de cultivo de tabaco no Rio Grande do Sul: o caso de Dom Feliciano-RS. Revista IDeAS, Rio de Janeiro, v. 7, n. 2, p. 176-213, 2013.

DEPONTI, C. M. Desmistificando a intervenção para o desenvolvimento à luz da perspectiva orientada ao ator. In: CONGRESSO BRASILEIRO DE SISTEMAS DE PRODUÇÃO, 6., 2007, Fortaleza, Anais... Fortaleza: VII Congresso Brasileiro de Sistemas de Produção. 2007.

GAZOLLA, M. Conhecimentos, produção de novidades e ações institucionais: cadeias curtas das agroindústrias familiares. Tese (Doutorado em Desenvolvimento Rural). Programa de Pós-graduação em Desenvolvimento Rural, UFRGS, Porto Alegre, 2012.

\section{GREGOLIN, A. Ações do Ministério de Desenvolvimento Agrário para a} diversificação da produção em áreas cultivadas com Tabaco no Brasil. Brasilia: MDA, 2010. 36p.

IBGE - Instituto Brasileiro de Geografia e Estatística. Produção Agrícola Municipal (PAM). Disponível em https://sidra.ibge.gov.br/tabela/5457\#resultado. Acesso em 28 de agosto de 2019.

. Censo Demográfico 2010: População residente, por situação do domicílio, sexo e idade, segundo a condição no domicílio e compartilhamento da responsabilidade do domicílio. Disponível em https://sidra.ibge.gov.br/tabela/1378\#resultado. Acesso em 28 de agosto de 2019.

LA VIA CAMPESINA. Naciones Unidas: El Tercer Comité aprueba la Declaración sobre Derechos Campesinxs y otras personas que trabajan en áreas rurales (2018). Disponível em: https://viacampesina.org/es/naciones-unidas-el-tercer-comiteaprueba-la-declaracion-sobre-derechos-campesinxs-y-otras-personas-que-trabajanen-areas-rurales/. Acesso 0: 27 junho de 2019.

LONG, N. Development Sociology: actor perspectives. London and New York: Routledge, 2001, 293p.

LONG, N. Sociología del desarrollo: una perspectiva centrada en el actor. México, Centro de Investigaciones y Estudios Superiores en Antropología Social: El Colegio de San Luis. 2007. 504 p.

LONG, N.; PLOEG, J. V. Heterogeneidade, ator e estrutura: para a reconstituição do conceito de estrutura. In: SCHNEIDER, S. e GAZOLLA, M.(Org.). Os atores do 
A geração de conhecimento e as inovações sócio-organizativas da agricultura familiar: O caso de Dom Feliciano, RS

desenvolvimento rural: perspectivas teóricas e práticas sociais. Porto Alegre: UFRGS Editora, 2011. p. x1-x2.

MAFFINI, P.R.; LEMOS, J.A.L. Plano Municipal de Desenvolvimento 2001-2004: manuscrito. 2001.

MEDEIROS, Monique; MARQUES, Flávia Charão. "Interfaces e transformações de práticas e conhecimentos na agricultura: um ensaio bibliográfico sobre a emergência das novidades". In: Revista IDeAS - Interfaces em Desenvolvimento, Agricultura e Sociedade, Rio de Janeiro - RJ, v. 5, n.1, p. 66- 90, 2011.

MENGEL, A. A. Tratados internacionais e disputas locais: A Convenção Quadro para o Controle do Tabaco e as disputas entre os atores da cadeia produtiva no Brasil. 2011. Dissertação (Mestrado em Desenvolvimento, Agricultura e Sociedade), Programa de Pós-Graduação de Ciências Sociais em Desenvolvimento, Agricultura e Sociedade, Instituto de Ciências Humanas e Sociais, UFRRJ, Rio de Janeiro, 2011.

OLIVEIRA, M. M. Como fazer pesquisa qualitativa. 5. ed. Petrópolis, RJ: Vozes, 2013.

QUADROS, C. S. Estudo de caso: Cooperativa Agropecuária Centro Sul (Coopacs). Bacharelado em Desenvolvimento Rural (PLAGEDER-UFRGS). São Lourenço do Sul. 2018.

RUDNICKI, C. S.; GUERIN, Y. S. As mediações na trajetória de vida dos agricultores do tabaco no Rio Grande do Sul. Revista Extensão Rural, DEAER - CCR - UFSM, v. 20, n. 1, p. 27-36, jan./mar. 2014.

SCHNEIDER, S.; MENEZES, M.A. 2014. "Inovação e atores sociais". In: SCHNEIDER, S.; MENEZES, M.A.; SILVA, A.G. da. BEZERRA, I. (Org.). Sementes e brotos da transição: inovação, poder e desenvolvimento em áreas rurais do Brasil. Porto Alegre: Editora da UFRGS, p.13-12.

SCHNEIDER, S.; MENEZES, M.A.; SILVA, A.G. da; BEZERRA, I. "Semeando sementes e cultivando brotos". In: SCHNEIDER, S.; MENEZES, M.A.; SILVA, A.G. da; BEZERRA, I. (Org.). Sementes e brotos da transição: inovação, poder e desenvolvimento em áreas rurais do Brasil. Porto Alegre: Editora da UFRGS, 2014. p.07-12.

SINDITABACO - Sindicato da Indústria do Tabaco. 15 maiores produtores de tabaco. Disponível em http://www.sinditabaco.com.br/sobre-o-setor/infograficos/. Acesso em 28 de agosto de 2019.

TRICHES, R. M. et al. O Programa de Alimentação Escolar nutrindo o desenvolvimento: ideias e relações inovadoras. In: SCHNEIDER, S. et al. (Org.). Sementes e brotos da transição: inovação, poder e desenvolvimento em áreas rurais do Brasil. 1. ed. Porto Alegre: UFRGS, 2014. p. 115-139. 
Leonardo Xavier Da Silva. Graduado em Ciências Econômicas (PUCRS), mestre em Economia Rural e doutor em Economia (UFRGS). Professor do Departamento de Economia e do Programa de Pós-Graduação em Desenvolvimento Rural (PGDR/UFRGS). leonardo.xavier@ufrgs.br.

Dagoberto de Dios Hernández. Ingeniero en Desarrollo e Innovación Empresarial (UTC), maestro en Desarrollo Económico Local (UAN) y doctorando en Desarrollo Rural (UFRGS). Asistente de investigación del cuerpo académico Actores Sociales y Desarrollo Comunitario, de la Universidad Autónoma de Nayarit (UAN), México. E-mail: dagobertodediosh@gmail.com.

Jesús Antonio Madera Pacheco. Licenciado en Economía (UAN), Maestro en Desarrollo Regional (COLEF) y doctor en Agroecología, Sociología y Desarrollo Rural Sostenible (UCO). Profesor-investigador en el Área de Ciencias Sociales y Humanidades de la Universidad Autónoma de Nayarit (UAN), México. E-mail: jmadera@uan.edu.mx.

Como citar: DA SILVA, Leonardo Xavier; DE DIOS HERNÁNDEZ, Dagoberto; MADERA PACHECO, Jesús Antonio. A geração de conhecimento e as inovações sócio-organizativas da agricultura familiar: O caso de Dom Feliciano, RS. Redes (St. Cruz Sul, Online), Santa Cruz do Sul, v. 25, n. 1, jan. 2020. ISSN 1982-6745. DOI: https://doi.org/10.17058/redes.v25i1.14100

\section{CONTRIBUIÇÃO DE CADA AUTOR}

Leonardo Xavier da Silva

- Foi responsável pela pesquisa dos dados e a análise estatística das informações coletadas na FEEDADOS, IBGE e outras fontes. Contribui com a problematização do tema central do artigo, com a seleção das referencias bibliográficas e realizou uma revisão à redação do texto.

Dagoberto de Dios Hernández

- Sua contribuição residiu na formulação e construção da ideia central do artigo. Realizou a redação geral do documento, da fundamentação teórica-conceitual, da proposta metodológica, assim como a elaboração de figuras e a seleção das referencias bibliográficas.

Jesús Antonio Madera Pacheco

- Contribui com a fundamentação teórico-conceitual em torno a Perspectiva Orientada ao Ator e aos Processos de Construção de Conhecimentos, assim como com a proposta metodológica. Participou também da elaboração e redação do texto, e da seleção das referencias bibliográficas. 